\title{
Regulation of the tension of human chorionic vasculature by histamine and prostaglandin $\mathbf{F}_{2 \alpha}$
}

\author{
CAROLYN W. QUIST, DO \\ ROBERT C. ADAMS, DO \\ EUGENE E. QUIST, PhD
}

\begin{abstract}
The calcium dependence of potassium chloride-, prostaglandin $\mathbf{F}_{2 \alpha}$ $\left(\mathrm{PGF}_{2 \alpha}\right)$-, and histamine-induced contractions of human chorionic vasculature segments was investigated. In physiologic buffer that contained $1.5 \mathrm{mM}$ calcium chloride, $60 \mathrm{mM}$ potassium chloride induced a rapid and sustained contraction of the vasculature. Potassium chloride-induced contractions were completely inhibited by the calcium channel blockers diltiazem and nifedipine or by excluding $\mathrm{Ca}^{2+}$ from the medium. Histamine $(100 \mu \mathrm{M})$ induced a rapid increase in vascular tension in physiologic buffer which rapidly faded or desensitized after maximal tension was obtained. The maximal contractile responses to histamine were reduced approximately $50 \%$ by diltiazem and nifedipine in physiologic buffer or by suspension in calciumfree medium (0CaPB). Pretreatment of vessels with $20 \mathrm{mM}$ caffeine in $0 \mathrm{CaPB}$ completely abolished histamine-dependent contractile responses. Prostaglandin $F_{2 \alpha}(100$ $\mathbf{n M}$ )-induced increases in vascular tension

From the Texas College of Osteopathic Medicine, Fort Worth, Tex. Dr Carolyn W. Quist is assistant professor, Department of Obstetrics and Gynecology; Dr Adams is chairman and associate professor, Department of Obstetrics and Gynecology; and Dr Eugene E. Quist is associate professor, Department of Pharmacology.

Reprint requests to Carolyn W. Quist, DO, Department of Obstetrics and Gynecology, Texas College of Osteopathic Medicine, 3500 Camp Bowie Blvd, ME 1, Rm 536, Fort Worth, Tx 76107-2690.
\end{abstract}

developed slowly but remained maximal for at least 40 minutes. Contractile responses to $\mathrm{PGF}_{2 \alpha}$ were reduced $50 \%$ to $65 \%$ by diltiazem and nifedipine in physiologic buffer or by suspension in 0CaPB. Caffeine pretreatment failed to alter the contractile response to $\mathrm{PGF}_{2 \alpha}$ in $0 \mathrm{CaPB}$. The differences in responsiveness of potassium chloride, histamine, and $\mathrm{PGF}_{2 \alpha}$ under the various conditions used suggest that these agents act by different mechanisms to elicit contractions in chorionic vessels. The potential roles of $\mathbf{P G F}_{2 \alpha}$, histamine, and calcium channel blockers in modulating the fetoplacental circulation is discussed.

(Key words: Placenta, vascular tension, autacoids, calcium channel blockers)

Fetal distress has been defined as a state of jeopardy of the fetus that, if untreated, leads to significant neonatal morbidity and mortality. Early investigative efforts correlated fetal distress with insufficient oxygen supply to the fetus secondary to a reduction in either uteroplacental or fetoplacental blood flow. Hypoxemia in the fetus results in a shift from aerobic to anaerobic metabolism with the accumulation of lactic acid which ultimately causes fetal brain cells to swell and rupture. With sufficient brain cell necrosis, fetal damage or death will occur.

The mechanisms regulating fetoplacental 
blood flow in the term human infant are not completely understood, but factors regulating the small-diameter resistance vessels of the placenta are believed to be important in this regard. ${ }^{1}$ Because placental vasculature lacks direct innervation, fetoplacental blood flow appears to be regulated by vasoactive substances. $^{2}$ The levels of numerous vasoconstrictive substances-such as prostaglandin $\mathrm{F}_{2 \alpha}$ $\left(\mathrm{PGF}_{2 \alpha}\right)$-increase dramatically in the fetoplacental circulation at the time of labor, ${ }^{3-6}$ and contract chorionic and umbilical cord vasculature. $^{7-11}$

The walls of the resistance arteries supplying individual exchange villi have been shown to be a site of synthesis of prostaglandins in the human fetus. In addition, the release of prostaglandins by placental tissue has been demonstrated in the presence of acute hypoxia. ${ }^{12}$ Therefore, vasoconstrictive agents, such as $\mathrm{PGF}_{2 \alpha}$, may be involved in regulating fetoplacental blood flow by constricting the resistance vessels in the chorion and villi. A reduction in fetal blood flow induced by these agents could contribute to fetal distress and hypoxia during labor.

Current efforts to treat such problems amount to controlling the maternal symptoms and are not aimed at the primary disorder. If these vasoactive agents could be shown to have direct effects on the regulatory role of the blood flow, antagonists might promote reversal of this distress. Because vascular smooth muscle and myometrial contractions are inhibited by calcium channel blockers, ${ }^{13,14}$ these vasorelaxing agents may improve perfusion to the fetus and decrease fetal distress and, therefore, warrant further study.

In this study, the contractile effects of $\mathrm{PGF}_{2 \alpha}$, histamine, and potassium chloride on segments of human chorionic plate vasculature were investigated. Although it has not been previously reported, we found that histamine strongly contracted these vessels. The dependence of these agents on extracellular and intracellular calcium sources for their contractile effects was also investigated.

\section{Materials and methods}

Human placentas were obtained from normal un- complicated term pregnancies of women delivered vaginally or by cesarean section. The following criteria were used to define normal pregnancies: a gestational age of between 37 and 42 weeks; no overt maternal medical complications; and no neonatal or gross placental abnormalities, including the absence of meconium staining. Placental vessels (arteries and veins) were dissected from the chorionic plate and placed in physiologic buffer at $5^{\circ} \mathrm{C}$ within 10 to 30 minutes of delivery. Physiologic buffer consisted of $10 \mathrm{mM}$ 4-(2-hydroxyethyl)-1piperazine-ethanesulfonic acid (HEPES) $(\mathrm{pH}, 7.4)$, $130 \mathrm{mM}$ sodium chloride, $5 \mathrm{mM}$ potassium chloride, $0.3 \mathrm{mM}$ potassium dihydrogen phosphate $\left(\mathrm{KH}_{2} \mathrm{PO}_{4}, 10 \mathrm{mM}\right.$ glucose, $1 \mathrm{mM}$ magnesium chloride, and $1.5 \mathrm{mM}$ calcium chloride. Placental vessels were maintained at $5^{\circ} \mathrm{C}$ and used over a period of 0 to 3 days.

Vessels were cut into two 6-mm tubular segments. One half was used for the control and the other half for drug treatment studies. Tubular vessel segments (average diameter, 1 to $3 \mathrm{~mm}$ ) were then fitted with triangles of No. 4 surgical steel wire, horizontally suspended in oxygenated water baths containing $18 \mathrm{~mL}$ of physiologic buffer at $37^{\circ} \mathrm{C}$, and attached to a Grass transducer (Grass Instruments, Quincy, Mass). ${ }^{11}$ The vascular preparations were equilibrated for 30 minutes and the tension was adjusted every 15 minutes by $1.0 \mathrm{~g}$ increments until a final resting tension of approximately $1.0 \mathrm{~g}$ was obtained.

Each set of vessels was standardized with $60 \mathrm{mM}$ potassium chloride solution at the beginning of each experiment. Subsequently, the vessels were washed with physiologic buffer, or modified physiologic buffer and allowed to relax and equilibrate. After 60 minutes, the vessels were challenged with either histamine or $\mathrm{PGF}_{2 \alpha}$. Next, various drugs were added directly to the bath medium to determine the presence or absence of calcium dependence on the contractile responses produced by histamine or $\mathrm{PGF}_{2 \alpha}$. Changes in tension were recorded with a Narco physiograph (Narco BioSystems, Inc, Houston, Tex). Studies showed that storing the vessels in physiologic buffer at $5^{\circ} \mathrm{C}$ for up to 3 days did not alter their responsiveness to potassium chloride, or $\mathrm{PGF}_{2 \alpha}$, or histamine. The dose response studies were performed by adding cumulative doses of $\mathrm{PGF}_{2 \alpha}$, or histamine in physiologic buffer to the chamber bath.

\section{Results}

Effects of potassium chloride on tension

In preliminary studies, the effect of membrane 
depolarizing concentrations of potassium chloride on chorionic vascular tension was examined. Potassium chloride $(60 \mathrm{mM})$ induced tension increases ranging from 1.4 to $3.0 \mathrm{~g}$ in physiologic buffer which contained $1.5 \mathrm{mM}$ calcium chloride (Figure 1). Half-maximal contractile responses induced by potassium chloride were obtained within 2 to 3 minutes and maximal contractions were sustained for at least $40 \mathrm{~min}$ utes. Vessels that were first contracted in 60 $\mathrm{mM}$ potassium chloride medium relaxed to baseline tension within 10 minutes when suspended in physiologic buffer or in calciumfree medium $(0 \mathrm{CaPB}$ ) containing $0.1 \mathrm{mM}$ (ethylene glycol bis ( $\beta$-aminoethyl ether) $\mathrm{N}, \mathrm{N}^{\prime}$ tetraacetic acid (EGTA) (Figure 1). Preincubating the vessels with $10 \mu \mathrm{M}$ diltiazem or 1 $\mu \mathrm{M}$ nifedipine almost completely blocked $(>90 \%)$ the contractile response caused by 60 $\mathrm{mM}$ potassium chloride (Figure 1 and Table). Furthermore, potassium chloride was unable to induce contractions in $0 \mathrm{CaPB}$ (Figure 1 and Table). Together, these observations suggest that potassium chloride-induced contractions were totally dependent on extracellular $\mathrm{Ca}^{2+}$ influx through voltage-dependent, L-type channels. ${ }^{15}$

\section{Effects of $\mathrm{PGF}_{2 \alpha}$ and histamine on tension in physiologic buffer}

Prostaglandin $\mathrm{F}_{2 \alpha}$ (10 to $\left.150 \mathrm{nM}\right)$ induced slow but relatively strong increases in chorionic vasculature tension (Figure 1). Half-maximal increases in tension were obtained with approximately $25 \mathrm{nM} \mathrm{PGF}{ }_{2 \alpha}$, and maximal contractions were obtained with $100 \mathrm{nM} \mathrm{PGF}_{2 \alpha}$ (Figures 1 and 2). Maximal tension changes were sustained for at least 40 minutes without fading in the presence of $\mathrm{PGF}_{2 \alpha}$.

Histamine (50 to $100 \mu \mathrm{M}$ ) was found to increase chorionic vasculature tension as well (Figures 1 and 2). Half-maximal and maximal increase in tension were induced by approximately $32 \mu \mathrm{M}$ and $80 \mu \mathrm{M}$ histamine, respectively. The rate of histamine-induced contractions was more rapid than with $\mathrm{PGF}_{2 \alpha}$, but maximal histamine-induced contractions were not sustained for more than 2 to 5 minutes. In the presence of histamine, the vessels spontaneously relaxed to half maximal tension in
10 to 20 minutes. The muscle tension then remained above baseline for at least 90 minutes in most vessel preparations (Figure 3). If vessels were first challenged with $100 \mu \mathrm{M}$ histamine to produce maximal tension and then immediately washed with physiologic buffer before the vessels relaxed, the maximal tension increase of a second dose of histamine was only $63 \%$ of the first. Immediate washing with physiologic buffer and a third histamine challenge produced an even smaller response (39\%) (Figure 3 ). These studies indicate that histamine responses in chorionic vessels are subject to desensitization, consistent with studies in other vascular beds. ${ }^{16}$ The histamine responses were strongly attenuated by $5 \mu \mathrm{M}$ pyrilamine, an $\mathrm{H}_{1}$ antagonist, but not by $5 \mu \mathrm{M}$ cimetidine, an $\mathrm{H}_{2}$ antagonist, showing that histamine acts on $\mathrm{H}_{1}$ receptors to induce contractions in these vessels.

\section{Calcium dependence of $P G F_{2 \alpha}$ and histamine}

The dependence of $\mathrm{PGF}_{2 \alpha}$ - and histamine-induced contractions on external calcium was examined by suspending tissue in $0 \mathrm{CaPB}$ or in physiologic buffer containing diltiazem or nifedipine. In $0 \mathrm{CaPB}$, the vessels relaxed slightly by $0.1 \mathrm{~g}$ before establishing a new baseline. The maximal tension induced by $100 \mathrm{nM}$ $\mathrm{PGF}_{2 \alpha}$ on $0 \mathrm{CaPB}$ was only $0.8 \mathrm{~g}$ or $33 \%$ of the maximal response obtained in physiologic buffer (Table 1 and Figure 1). However, the maximal contraction obtained in $0 \mathrm{CaPB}$ was sustained for at least 40 minutes. Pretreatment of vessels with $20 \mathrm{mM}$ caffeine in $0 \mathrm{CaPB}$ to deplete sarcoplasmic reticulum $\mathrm{Ca}^{2+}$ did not affect the responsiveness to $100 \mathrm{nM} \mathrm{PGF}_{2 \alpha}$ (Figure 4). However, caffeine by itself provoked a small and transient increase in tension, presumably because of the release of intracellu$\operatorname{lar} \mathrm{Ca}^{2+}$.

Maximal histamine-induced contractions were approximately $50 \%$ lower in $0 \mathrm{CaPB}$ than in physiologic buffer (Table and Figure 1). In the absence of extracellular $\mathrm{Ca}^{2+}$, the vessels completely relaxed to baseline within 20 to 30 minutes (Figures 1 and 4 ). In vessels preincubated with $20 \mathrm{mM}$ caffeine in $0 \mathrm{CaPB}$, histamine no longer had any significant contrac- 


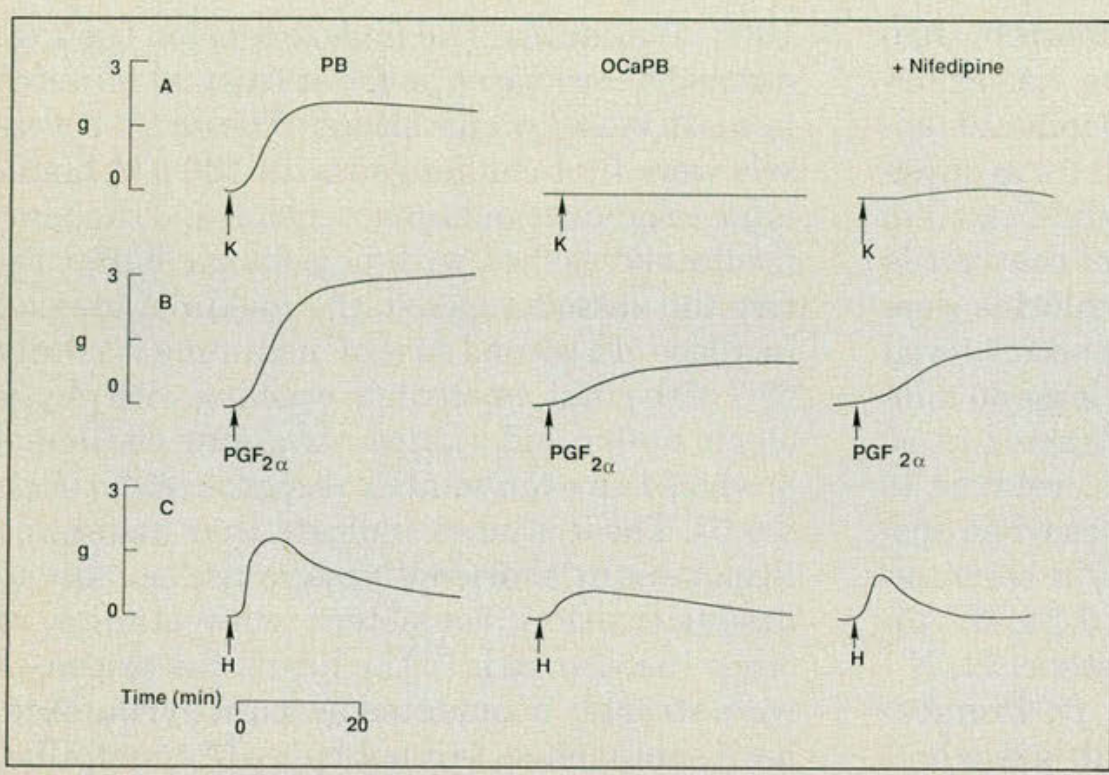

Figure 1. Contractile responses induced by $60 \mathrm{mM}$ potassium chloride $(K)$, $100 \mathrm{nM}$ prostaglandin $F_{2 \alpha}\left(P G F_{2 \alpha}\right)$, and $100 \mu \mathrm{M}$ histamine $(H)$ in physiological buffer $(P B)$, calcium-free medium (OCaPB), and physiologic buffer $+1 \mu M$ nifedipine. Tracings are representative of one experiment. Similar results have been obtained in at least two other separate experiments.

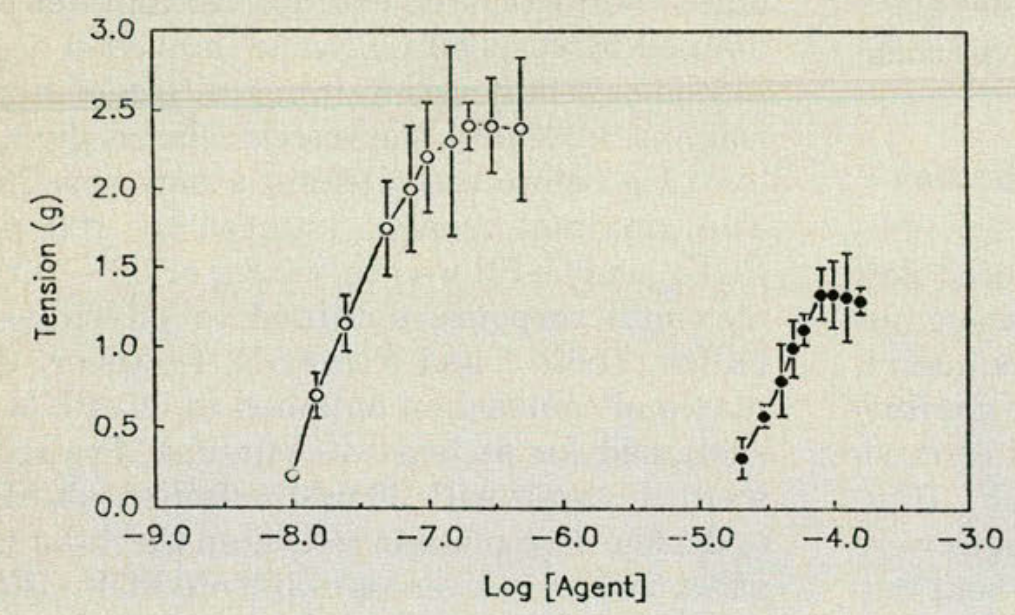

Figure 2. Dose dependence for $P G F_{2 \alpha}$ (open circle) and histamine (solid circle) in human chorionic vasculature. Results are representative of 3 experiments performed in quadruplicate. Values represent the mean $\pm S D$.

tile effect, although in control vessels preincubated in $0 \mathrm{CaPB}$ without caffeine, histamine increased tension by $0.6 \mathrm{~g}$ (Figure 4 ).

The effect of pretreating vessels with maximally effective concentrations of the calcium channel blockers, nifedipine and diltiazem, was tested. In vessels preincubated $10 \mathrm{~min}$ utes in physiologic buffer with $1 \mu \mathrm{M}$ nifedipine or $10 \mu \mathrm{M}$ diltiazem, the contractile responses to $100 \mathrm{nM} \mathrm{PGF}_{2 \alpha}$ were $49 \%$ and $46 \%$ of the maximal responses obtained in physiologic buffer (Table and Figure 1). Contractile responses to 100 $\mu \mathrm{M}$ histamine were $49 \%$ to $57 \%$ of maximum in vessels preincubated with nifedipine and diltiazem, respectively.

\section{Discussion}

In this study, potassium chloride, $\mathrm{PGF}_{2 \alpha}$, and histamine were shown to produce strong contractile responses in human chorionic vasculature. Since calcium is known to play an important role in the activation of smooth muscle contractile proteins, ${ }^{15,17-21}$ the calcium requirements for these vasoconstrictorinduced contractions were examined. Although this study originally focused on the contractile responses to $\mathrm{PGF}_{2 \alpha}$ and histamine, comparative studies with potassium chloride were also included because the mechanism of potassium chloride-induced contractions is better understood.

High concentrations of extracellular potassium chloride depolarize vascular smooth muscle cells to "open" voltagedependent L-type calcium channels, whereby extracellular $\mathrm{Ca}^{2+}$ can enter the cell down its concentration gradient to stimulate contractile proteins. Calcium channel blockers such as diltiazem or nifedipine inactivate L-type channels and, therefore, prevent $\mathrm{Ca}^{2+}$ influx into the cells. Consistent with this mechanism, potassium chloride-depend- 
ent contractions of human chorionic vessels were shown here to be prevented by diltiazem and nifedipine in physiologic buffer or abolished in $\mathrm{Ca}^{2+}$-free medium.

\section{Pharmacologic effects of $P G_{2 \alpha}$ and histamine}

In agreement with previous studies, ${ }^{6-10} \mathrm{PGF}_{2 \alpha}$ strongly contracted human placental chorionic vessels. The rate of induction of contractile responses to $\mathrm{PGF}_{2 \alpha}$ were relatively slow, but maximal contractions were sustained and, thus, were not characterized by desensitization (Figure 1 ). In comparison, histamine induced more rapid contractile responses which were relatively transient in duration. Exposure of the vasculature to single or repeated doses of histamine resulted in the loss of contractile responsiveness (Figures 1 and 3 ). The mechanism(s) for desensitization are not well understood, but increases in intracellular calcium and/or stimulation of protein kinases have been implicated. ${ }^{15,22,23}$

Increased intracellular calcium could not be solely responsible for desensitization because potassium chloride- and $\mathrm{PGF}_{2 \alpha}$-induced responses did not desensitize. However, the response to histamine faded faster in $0 \mathrm{CaPB}$ than in physiologic buffer, suggesting that dissipation of intracellular calcium stores may be contributory. Clearly, further studies will be required to resolve the mechanism(s) involved in desensitization, and a comparison of the biochemical responses evoked by $\mathrm{PGF}_{2 \alpha}$ and histamine may be useful to further understand the mechanisms regulating contrac-
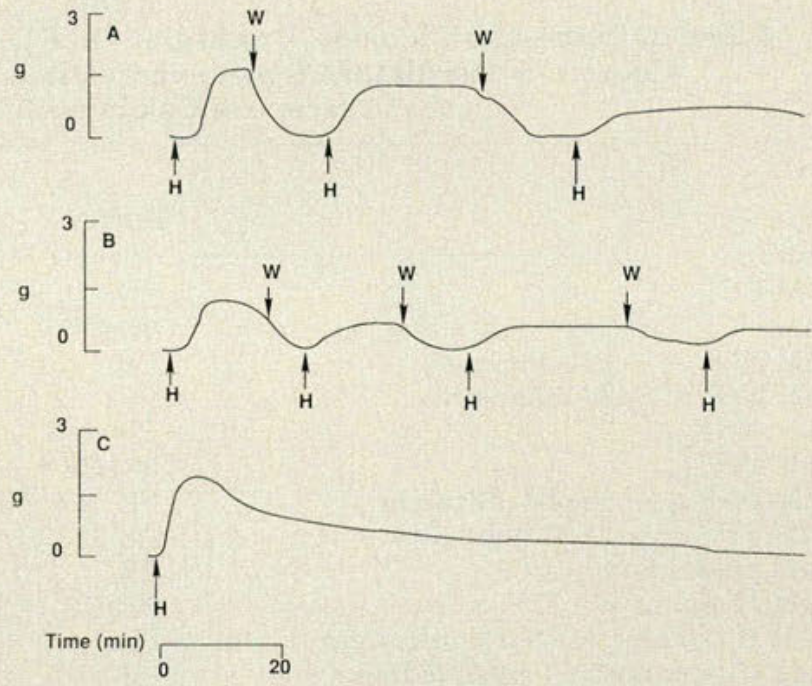

Figure 3. Effect of repetitive and single doses of histamine on chorionic vessel tension. A and B represent effects of multiple doses of $100 \mu M$ histamine $(H)$ on contractions. Vessels are washed $(W)$ between doses with physiologic buffer. $C$ shows the time course of a single dose of $100 \mu M$ histamine.
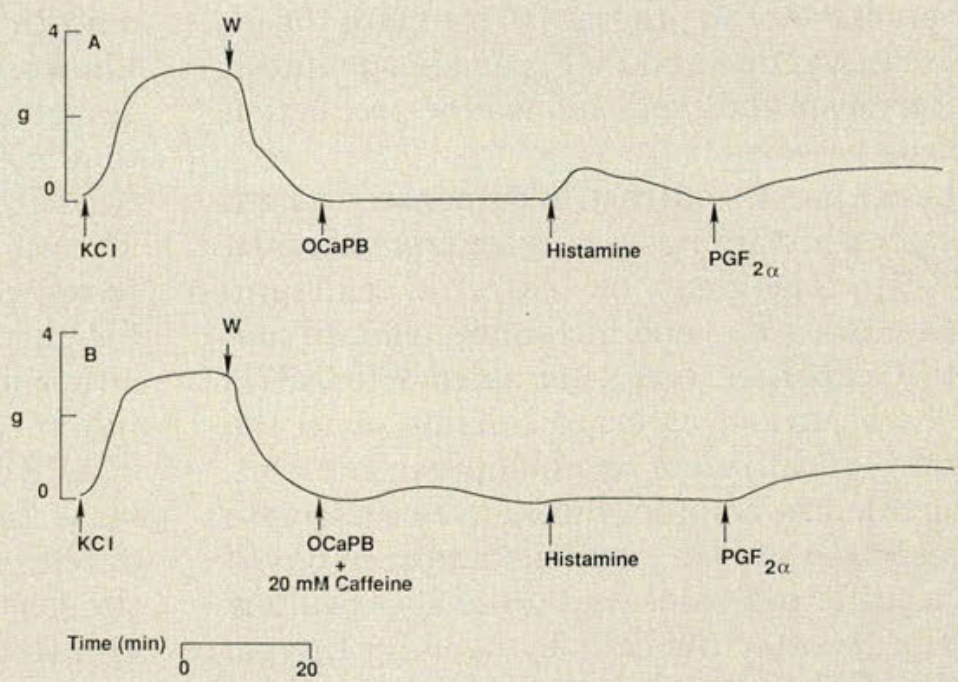

Figure 4. Histamine and $P G F_{2 \alpha}$ contractile responses in vessels suspended in $0 \mathrm{CaPB}(A)$ or in $0 \mathrm{CaPB}+20 \mathrm{mM}$ caffeine $(B)$. Paired vessels were first contracted with $60 \mathrm{mM}$ potassium chloride in physiologic buffer and then suspended in $0 C a P B$. After pretreatment with either $0 C a P B$ or $0 C a P B+20 \mathrm{mM}$

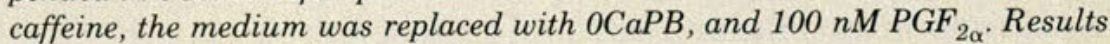
are representative of four experiments. tion in human chorionic vessels. The results of this investigation suggest that $\mathrm{PGF}_{2 \alpha}$ and histamine must invoke different biochemical mechanisms (although some pathways may be shared) to contract chorionic vasculature. Fur- 
Table

Effect of Potassium Chloride, Prostaglandin $\mathrm{F}_{2 \alpha},\left(\mathrm{PGF}_{2 \alpha}\right)$, and Histamine on Human Chorionic Vasculature Tension in Calcium-Free Medium (0CaPB) and in the Presence of Calcium Channel Blockers*

\begin{tabular}{|llr|}
\hline Agent & Buffer & $\begin{array}{c}\text { Maximal } \\
\text { tension }\end{array}$ \\
\hline A $60 \mathrm{mM} \mathrm{KCl}$ & PB* & 100 \\
& Inhibition
\end{tabular}

ther studies are in progress to compare the effects of histamine and $\mathrm{PGF}_{2 \alpha}$ on phosphoinositide turnover and cyclic nucleotide production in these vessels.

The maximal contractile responses to both $\mathrm{PGF}_{2 \alpha}$ and histamine were approximately $50 \%$ to $70 \%$, dependent on external calcium. Prostaglandin $\mathrm{F}_{2 \alpha}$ - and histamine-induced contractile responses were attenuated $46 \%$ to $67 \%$ in the absence of external calcium or in the presence of diltiazem or nifedipine. The ability of calcium channel blockers to attenuate the responses of $\mathrm{PGF}_{2 \alpha}$ and histamine in physiologic buffer indicates that these agents allow calcium to enter the cells by opening L-type, voltage-dependent calcium channels or receptor-operated channels. ${ }^{15}$ To account for $\mathrm{PGF}_{2 \alpha^{-}}$ and histamine-induced contractile responses in the absence of external calcium, these agents may either stimulate the release of calcium from intracellular stores or increase the sensitivity of contractile elements to calcium.

Prostaglandins have been observed to indirectly open receptor-operated $\mathrm{Ca}^{2+}$ channels and/or to release intracellular calcium in certain types of smooth muscle cells, ${ }^{24,25}$ and in human placental arteries. ${ }^{13,14}$ Histamine also increases cytosolic $\mathrm{Ca}^{2+}$ in certain vascular smooth muscle beds. ${ }^{13,22}$ Caffeine, an agent known to release and deplete $\mathrm{Ca}^{2+}$ from the sarcoplasmic reticulum, ${ }^{15}$ was shown here not to affect the contractile response to $\mathrm{PGF}_{2 \alpha}$ in $0 \mathrm{CaPB}$ but abolished the histamine responses. Therefore, histamine but not $\mathrm{PGF}_{2 \alpha}$ appears to rely on sarcoplasmic reticulum $\mathrm{Ca}^{2+}$ stores for part of its effect. It is likely that $\mathrm{PGF}_{2 \alpha}$ either utilizes a caffeine insensitive intracellular calcium pool or the response observed in $0 \mathrm{CaPB}$ may not be dependent on calcium release. In other vascular beds, various vasoconstrictors may activate $\mathrm{G}$ proteins to increase the $\mathrm{Ca}^{2+}$ sensitivity of myosin light chain kinase ${ }^{26}$ without increases in cytosolic $\mathrm{Ca}^{2+}$ above resting levels.

\section{Clinical aspects of histamine and calcium channel blockers}

To our knowledge, this is the first report showing that histamine induces contractions of the human chorionic vasculature. Although the physiologic relevance of histamine-mediated contractions is unknown, certain speculations can be made. For instance, if histamine is released in response to antigens in pregnancy or in response to labor (as are prostaglandins), circulating or locally produced histamine could 
constrict chorionic vessels and reduce fetoplacental blood flow. Potentially, histamine could also constrict other vessels-such as umbilical arteries and veins-further compromising perfusion. Because histamine affects $\mathrm{H}_{1}$ receptors in these vessels, predictably $\mathrm{H}_{1}$ antagonists may oppose the effect of histamine and improve perfusion. At this time, the effects of antihistamines on fetoplacental blood flow are unknown, but theoretically these agents may have some usefulness in treating fetal hypoxia.

As noted by Maigaard and coworkers,${ }^{13}$ nifedipine markedly attenuated the contractile responses induced by $\mathrm{PGF}_{2 \alpha}$. Diltiazem was also found here to effectively attenuate $\mathrm{PGF}_{2 \alpha}$ responses, and both nifedipine and diltiazem attenuated responses to histamine. Because $\mathrm{PGF}_{2 \alpha}$ and possibly histamine may increase in the fetal circulation during labor, calcium channel blockers may improve fetoplacental perfusion. However, decreases in chorionic vascular resistance and a decrease in maternal vascular resistance could simultaneously decrease maternal uterine blood pressure and attenuate exchange of gases and nutrients across the uteroplacental unit. This dual action could thus offset any beneficial effects of vasodilation of chorionic vessels on the fetal side.

Diltiazem, in contrast to nifedipine, slightly depresses myocardial function by a direct mechanism ${ }^{27}$ and, therefore, potentially could have some depressing effect on the fetal heart. Another point is that reflex tachycardia is not as great with diltiazem as with nifedipine, and this difference may have some effect on the clinical outcome when these agents are used. The use of calcium channel blockers will require extensive clinical investigation and, therefore, they should be used cautiously until a better understanding of their pharmacologic responses can be ascertained.

\section{Acknowledgment}

The authors thank the staff of the Osteopathic Medical Center of Texas Labor and Delivery personnel for help in obtaining the placentas and Ranga Dasan for her excellent technical skills. The work was supported by a grant from the American $\mathrm{Col}$ - lege of Osteopathic Obstetricians and Gynecologists and the Mead Johnson Company.

$P G F_{2 \alpha}$ was donated by the Upjohn Company, Kalamazoo, Mich. Histamine, caffeine, pyrilamine, and EGTA were obtained from Sigma Chemical Company, St Louis, Mo. Diltiazem was supplied by Marion Laboratories, Inc, Kansas City, Mo, and nifedipine was obtained from the Pfizer Company, Brooklyn, NY.

\section{References}

1. Rankin JHG, and McLaughlin MK: The regulation of the placental blood flows. J Dev Physiol 1979;1:3-30.

2. Reilly FD, Russell PT: Neurohistochemical evidence supporting an absence of adrenergic and cholinergic innervation in the human placenta and umbilical cord. Anat Rec 1977;188:277-286. 3. Jonsson CE, Tuvemo T, Hamberg M: Prostaglandin biosynthesis in the human umbilical cord. Biol Neonate 1976;29:162170 .

4. Chard T, Hudson CN, Edwards CRW, et al: Release of oxytocin and vasopressin by the human foetus during labour. Nature 1971;234:352-353.

5. Walsh SW: Preeclampsia: An imbalance in placental prostacyclin and thromboxane production. Am J Obstet Gynecol 1985; 152:335-340.

6. Harper MJK, Khodr GS, Valenzuela G: Prostaglandin production by human term placentas in vitro. Prosta Leuko 1983;11:121-129.

7. Altura BM, Malaviya D, Reich CF, et al: Effects of vasoactive agents on isolated human umbilical arteries and veins. Am $J$ Physiol 1972;222:345-355.

8. Hillier K, Karim SMM: Effects of prostaglandins $\mathrm{E}_{1}, \mathrm{E}_{2}, \mathrm{~F}_{1} \alpha$, $\mathrm{F}_{2 \alpha}$ on isolated human umbilical and placental blood vessels. BrJ Obstet Gynecol 1968;75:667-673.

9. Tulenko TN: The actions of prostaglandins and cyclo-oxygenase inhibition on the resistance vessels supplying the human fetal placenta. Prostaglandins 1981;21:1033-1043.

10. Maigaard S, Forman A, Andersson K-E: Relaxant and contractile effects of some amines and prostanoids in myometrial and vascular smooth muscle within the human uteroplacental unit. Acta Physiol Scand 1986;128:33-40.

11. Maigaard S, Forman A, Andersson K-E: Differential effects of angiotensin, vasopressin, and oxytocin on various smooth muscle tissues within the human uteroplacental unit. Acta Physiol Scand 1986;128:23-31.

12. Ekblad U, Erkkola R, Uotila P: The effect of acute hypoxia on prostaglandin release in perfused human fetal placenta. Prostaglandins 1987;33:553-560.

13. Maigaard S, Forman A, Andersson K-E: Effects of nifedipine on human placental arteries. Gynecol Obstet Invest 1984;18:217-224.

14. Maigaard S, Forman A, Brogaard-Hansen KP, et al: Inhibitory effects of nitrendipine on myometrial and vascular smooth muscle in human pregnant uterus and placenta. Acta Pharmacol 1986;59:1-10.

15. van Breemen C, Saida K: Cellular mechanisms regulating $\left[\mathrm{Ca}^{2+}\right]_{\mathrm{i}}$ smooth muscle. Annu Rev Physiol 1989;51:315-329.

16. Brown RD, Prendiville P, Cain C: ${ }_{\alpha 1}$-Adrenergic and $\mathrm{H}_{1^{-}}$ histamine receptor control of intracellular $\mathrm{Ca}^{2+}$ in a muscle 
cell line: The influence of prior agonist exposure on receptor responsiveness. Mol Pharmacol 1986;29:531-539.

17. van Breemen C, Aaronson PI, Cauvin CA, et al: The calcium cycle in arterial smooth muscle, in Flaim SF, Zelis R (eds): Calcium blockers: Mechanisms of action and clinical application, Baltimore, Urban and Schwarzenberg, 1982, pp 53-63.

18. van Breemen C, Aaronson P, Loutzenhiser R: Sodiumcalcium interactions in mammalian smooth muscle. Pharmacol Rev 1979;30:167-208.

19. Meisheri KD, Hwang O, van Breemen C: Evidence for two separate $\mathrm{Ca}^{2+}$ pathways in smooth muscle plasmalemma. $J$ Membr Biol 1981;59:19-25.

20. Nishizuka Y: The role of protein kinase $\mathrm{C}$ in cell surface signal transduction and tumour promotion. Nature 1984;308:693698.

21. Kamm KE, Stull JT: The function of myosin and myosin light chain kinase phosphorylation in smooth muscle. Annu Rev Pharmacol Toxicol 1985;25:593-620.

22. Pollock WK, Wreggett KA, Irvine RF: Inositol phosphate production and $\mathrm{Ca}^{2+}$ mobilization in human umbilical-vein endothelial cells stimulated by thrombin and histamine. Biochem J 1988;256:371-376.

23. Putney JW, Takemura H, Hughes AR, et al: How do inositol phosphates regulate calcium signaling? Fed Proc 1986;3:1899. 1905.

24. Deth R, Casteels R: A study of releasable Ca fractions in smooth muscle cells of the rabbit aorta. J Gen Physiol 1977;69:401-416.

25. Deth R, van Breemen C: Agonist induced release of intracellular $\mathrm{Ca}^{2+}$ in the rabbit aorta. J Memb Biol 1977;30:363-380.

26. Kitazawa T, Gaylinn BD, Denney GH, et al: G-proteinmediated $\mathrm{Ca}^{2+}$ sensitization of smooth muscle contraction through myosin light chain phosphorylation. J Biol Chem 1991;266:1708-1715.

27. Murad F: Drugs used in the treatment of angina: Organic nitrates, calcium-channel blockers, and $\beta$-adrenergic antagonists, in Gilman AG, Rall TW, Nies AS, et al (eds): The Pharmacological Basis of Therapeutics, ed 8, New York, NY Pergamon Press, 1990, pp 774-780. 


\section{ciRDHA (diltiazem HCl)}
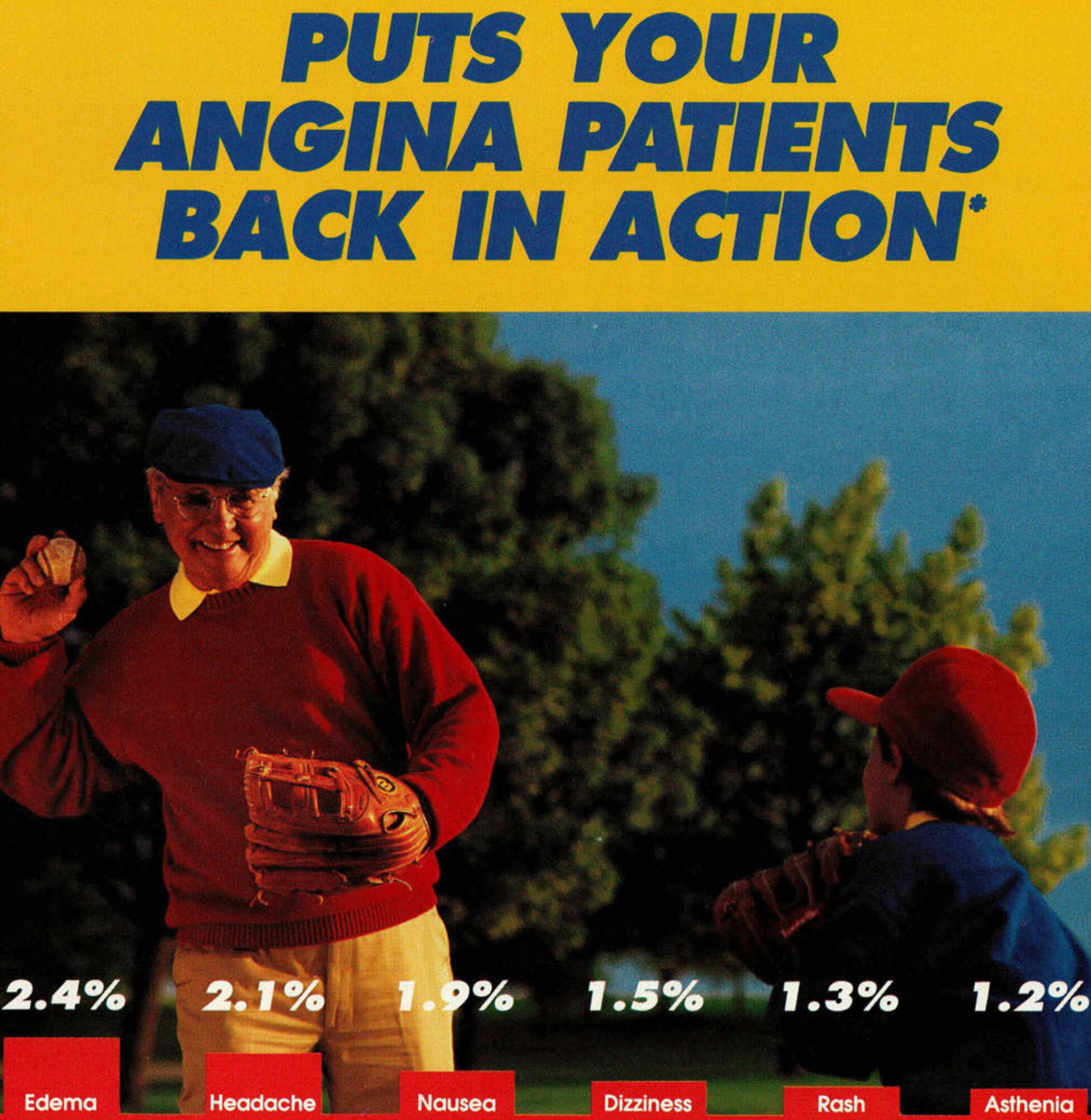

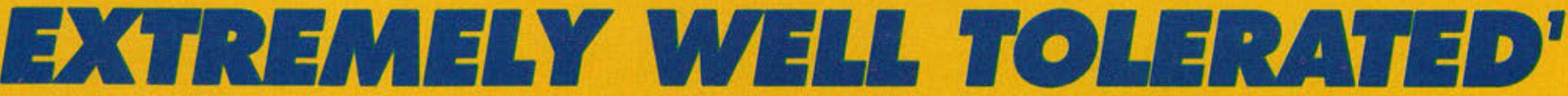

- CARDIZEM (diltiazem $\mathrm{HCl}$ ) is indicated in the treatment of angina pectoris due to coronary artery spasm and in the management of chronic stable angina (classic effort-associated angina) in patients who cannot tolerate therapy with beta-blockers and/or nitrates or who remain symptomatic despite adequate doses of these agents. 


\section{cii $12=51^{\circ}$ (diltiazem $\mathrm{HCl}$ )}

UNSURPASSED EFFICACY AND SAFETY

Unsurpassed reductions in the frequency of anginal episodes ${ }^{2-5}$

Unsurpassed increases in exercise tolerance ${ }^{2-4,6}$

References:

1. Data on file, Marion Merrell Dow Inc. 2. Frishman W. Charlap S. Kimmel B, et al. Circulation. 1988:77:774-786. 3. Klinke WP, Kvill L. Dempsey EE, Grace M. J Am Coll Cardiol. 1988:12:1562-1567. 4. Hung J. Lamb IH. Connolly SJ, Jutzy KR, Goris ML. Schroeder JS. Circulation. 1983;68:560-567. 5. L'Abbate A. Parodi O, Panciroli C. et al. Cardiology Board Review. 1989:6(suppl):50-54. 6. Anderson JL. Wagner JM. Datz FL. Christian PE, Bray BE. Taylor AT. Am Heart J. 1984:107:698-706.

\section{BRIEF SUMMARY}

\section{CARDIZEM⿻}

(dilitiazem hydrochioride) Tablets

\section{CONTRAINDICATIONS}

CARDIZEM is contraindicoted in (1) potients with sick sinus syndrome except in the presence of a functioning ventricular pocemaker, (2) patients with second- or third-degree AV block except in the presence of a functioning ventricular pocemaker, (3) patients with hypotension (less than $90 \mathrm{~mm} \mathrm{Hg}$ systolic), (4) patients who have demonstrated hypersensitivity to the drug, and (5) patients with acute myocardial infarction and pulmonary congestion documented by $x$-ray on odmission.

\section{WARNINGS}

Cardioc Conduction. CARDIZEM prolongs AV node refroctory periods without significantly prolonging sinus node recovery time, except in patients with sick sinus syndrome. This effect may rarely result in abnormally slow heart rotes (particularly in patients with sick sinus syndrome) or second- or third-degree AV block (six of 1.243 patients for $0.48 \%$ ). Concomitant use of diltiazem with beto-blockers or digitalis may result in odditive effects on cardioc conduction. A potient with Prinzmetol's an gina developed periods of asystole ( 2 to 5 seconds) after a single dose of $60 \mathrm{mg}$ of dilitiazem.

2. Congestive Heart Failure. Although diliazem has a negative inotropic effect in isolated animal tissue preparations, hemodynomic studies in humans with normal ventriculor function hove not shown a reduction in cardioc index nor consistent negative effects on contractility (dp/dt). Experience with the use of CARDIZEM alone or in combination with beto-blockers in potients with impoired ventricular function is very limited. Caution should be exercised when using the drug in such patients.

3. Hypotension. Decreoses in blood pressure associated with CARDIZEM therapy may occosionally result in symptomatic hypotension

4. Acute Hepatic Injury. In rore instances, significant elevations in enzymes such as alkoline phosphatose, LDH, SGOT, SGPI, and other phenomena consistent with ocute hepatic injury hove been noted. These reactions hove been reversible upon discontinuation of drug therapy. The relationship to CARDIZEM is uncertain in most cases, but probable in some. (See PRECAUTIONS.)

\section{PRECAUTIONS}

General. CARDIZEM (diltiazem hydrochloride) is extensively metabolized by the liver and excreted by the kidneys and in bile. As with any drug given over prolonged periods, laboratory parameters should be monitored at regular intervals. The drug should be used with coution in patients with impoired renal or hepatic function. In subocute and chronic dog and rat studies designed to produce toxicity, high doses of diltiozem were associated with hepatic domoge. In special subocute hepatic studies, orol doses of $125 \mathrm{mg} / \mathrm{kg}$ and higher in rats were associated with histological changes in the liver which were reversible when the drug wos discontinued. In dogs, doses of $20 \mathrm{mg} / \mathrm{kg}$ were also ossociated with hepatic changes; however, these changes were reversible with continued dosing.

Dermatological events (see ADVERSE REACTIONS section) moy be transient and may disappear despite continued use of CARDIZEM. However, skin eruptions progressing to erytherna multiforme and/or exfoliative dermatitis hove also been infrequently reported. Should a dermatologic reaction persist, the drug should be discontinued.

Drug Interoction. Due to the potential for additive effects, coution and careful tifration are warranted in patients receiving CARDIZEM concomitantly with any ogents known to affect cardiac contractility and/or conduction. (See WARNINGS.

Pharmocologic studies indicate that there may be odditive effects in prolonging AV conduction when using beto-blockers or digitalis concomitontly with CARDIZEM. (See WARNINGS)

As with all drugs, core should be exercised when treating potients with multiple medications. CARDIZEM undergoes biotrons formation by cytochrome P-450 mixed function oxidase Coodministration of CARDIZEM with other agents which follow the same route of biotransformation may result in the competitive inhibition of metabolism. Dosoges of similarly metabolized drugs, particularly those of low theropeutic ratio or in patients with renal and/or hepatic impairment, may require adjustment when starting or stopping concomitontly odministered CARDIZEM to maintoin optimum therapeutic blood levels.

Beta-blockers: Controlled and uncontrolled domestic studies suggest that concomitont use of CARDIZEM and beto-blockers or digitalis is usually well tolerated. Available data are not sufficient, however, to predict the effects of concomitant treatment, particularly in patients with left ventricular dysfunction or cardiac conduction abnormalities

Administrotion of CARDIZEM (diliazem hydrochloride) concomitontly with propronolol in five normol volunteers resulted in increased propranolol levels in all subjects and bioavailability of propranolol was increased approximately $50 \%$. If combination therapy is initiated or withdrawn in conjunction with propranolol, an adjustment in the propranolol dose may be warranted. (See WARNINGS.)

Cimetidine: A study in six heolthy volunteers has shown o significant increose in peok diltiazem plasma levels $(58 \%)$ and area-under-the-curve (53\%) after a 1-week course of cimetidine at $1,200 \mathrm{mg}$ per day and dilfiazem $60 \mathrm{mg}$ per day. Ranitidine produced smaller, nonsignificant increoses. The effect may be me diated by cimetidine's known inhibition of hepatic cytochrome P.450, the enzyme system probably responsible for the first-pass metabolism of ditiozem. Patients currently receiving diltiazem therapy should be carefully monitored for a change in pharmocologica effect when initiating and discontinuing theropy with cimetidine. An adjustment in the ditiazem dose may be warranted.

Digitalis: Administration of CARDIZEM with digoxin in 24 healthy male subjects increased plasma digoxin concentration approximately $20 \%$. Another investigator found no increase in digoxin levels in 12 potients with coronary artery diseose. Since there have been conflicting results regarding the effect of digoxin levels, it is recommended that digoxin levels be monitored when inifiating, odjusting, and discontinuing CARDIZEM theropy to avoid possible over- or under-digitolization. (See WARNINGS.)

Anesthetics: The depression of cardioc controctility, conductiv ity, and automaticily as well as the vascular dilation associated with anesthetics may be potentioted by calcium channel blockers. When used concomitantly, anesthetics and calcium blockers should be fitroted carefulty

Carcinogenesis, Mutogenesis, Impoirment of Fertility. A 24 month study in rats and a 21 -month study in mice showed no evidence of corcinogenicity. There wos also no mutogenic response in in vitro bocterial fests. No infrinsic effect on fertility was observed in rots

Pregnancy. Cotegory C. Reproduction studies have been conducted in mice, rats, and rabbits. Administration of doses ranging from five to ten times greater (on a mg/kg bosis) than the doily recommended theropeutic dose hos resulted in embryo and fetol lethality. These doses, in some studies, have been reported to couse skeletol abnormolities in the peringtol/postnatol studies, there wos some reduction in early individuol pup weights and survival rates. There was an increased incidence of stillbirths a doses of 20 times the human dose or grecter.
There are no well-controlled studies in pregnant women; therefore, use CARDIZEM in pregnant women only if the potential beneff justifies the potential risk to the fetus.

Nursing Mothers. Diltiozem is excreted in human milk. One report suggests that concentrations in breastmilkmoy opproximote serum levels. If use of CARDIZEM is deemed essential, an alternafive method of infant feeding should be instituted

Pediatric Use. Safety and effectiveness in children have not been estoblished.

\section{ADVERSE REACTIONS}

Serious odverse reoctions have been rore in studies corried out to Sere, but it should be recognized that patients with impoired ventriculor function and cardiac conduction abnormalities have usually been excluded

In domestic placebo-controlled angina trials, the incidence of adverse reactions reported during CARDIZEM therapy was not greater than that reported during placebo therapy.

The following represent occurrences observed in clinical studies Th angino potients. In mony coses, the relationship to CARDIZEM hos not been established. The most common occurrences from these studies, as well as their frequency of presentation are: edemo $(2.4 \%)$, headache $(2.1 \%)$, nauseo $(1.9 \%)$, dizziness $(1.5 \%)$ rash $(1.3 \%)$, asthenio $(1.2 \%)$. In oddition, the following events were reported infrequently (less than 1\%)

Cordiovascular: Angina, arrhythmia, AV block (first degree), AV block (second or third degree - see conduc fion worning), bradycardia, bundle branch block, congestive heart failure, ECG abnormality, flushing, hypotension, palpitations, syncope, tochycardia, ventricular extrosystoles

Nervous System: Abnormal dreams, amnesia, depression, go abnormality, hallucinations, insomnia, nervousness, paresthesia, personality change somnolence, tremor.

Gostrointestinal: Anorexio, constipation, diarrhea, dysgeusio, dyspepsio, mild eleyotions of alkaline phosphatose SGOT SGPT and LDH (see hepotic wornings), thirst, vomiting, weight increose.

Dermatological: Petechioe, photosensitivity, pruritus, urticaric

Other: $\quad$ Amblyopio, CPK elevation, dry mouth, dyspneo, epistoxis, eye irritation, hyperglycemia hyperuricemio, impotence, muscle cromps, nasal congestion, nocturia, osteocrticular poin polyuria, sexual difficulties, finnitus

The following postmarketing events have been reported infrequently in potients receiving CARDIZEM: alopecio, erythema multilorme, extropyramidal symptoms, gingival hyperplosia, hemolytic anemio, increased bleeding time, leukopenia, purpuro, retinopathy, and thrombocytopenia. There have been observed coses of a generalized rash, characterized as leukocytoclostic vosculitis. In oddition, events such as myocardial infarction have been observed which are not reodily distinguishable from the natural history of the diseose in these patients. A definitive cause ond effect relationship between these events and CARDIZEM therapy cannot yet be estoblished. Extoliative dermatitis (proven by rechallenge) has olso been reported

ssued 1/91

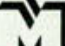

MARION MERRELL DOW INC. PRESCRIPTION PRODUCTS DIVISION 